\title{
Differential proteomic analysis highlights metabolic strategies associated with balhimycin production in Amycolatopsis balhimycina chemostat cultivations
}

\author{
Giuseppe Gallo ${ }^{1 *}$, Rosa Alduina', Giovanni Renzone ${ }^{2}$, Jette Thykaer ${ }^{3}$, Linda Bianco ${ }^{2}$, Anna Eliasson-Lantz ${ }^{3}$, \\ Andrea Scaloni ${ }^{2}$, Anna Maria Puglia ${ }^{1^{*}}$
}

\begin{abstract}
Background: Proteomics was recently used to reveal enzymes whose expression is associated with the production of the glycopeptide antibiotic balhimycin in Amycolatopsis balhimycina batch cultivations. Combining chemostat fermentation technology, where cells proliferate with constant parameters in a highly reproducible steady-state, and differential proteomics, the relationships between physiological status and metabolic pathways during antibiotic producing and non-producing conditions could be highlighted.
\end{abstract}

Results: Two minimal defined media, one with low Pi $(0.6 \mathrm{mM}$; LP) and proficient glucose $(12 \mathrm{~g} / \mathrm{l})$ concentrations and the other one with high $\mathrm{Pi}(1.8 \mathrm{mM})$ and limiting ( $6 \mathrm{~g} / \mathrm{l} ; \mathrm{LG})$ glucose concentrations, were developed to promote and repress antibiotic production, respectively, in A. balhimycina chemostat cultivations. Applying the same dilution rate $\left(0.03 \mathrm{~h}^{-1}\right)$, both LG and LP chemostat cultivations showed a stable steady-state where biomass production yield coefficients, calculated on glucose consumption, were $0.38 \pm 0.02$ and $0.33 \pm 0.02 \mathrm{~g} / \mathrm{g}$ (biomass dry weight/glucose), respectively. Notably, balhimycin was detected only in LP, where quantitative RT-PCR revealed upregulation of selected bal genes, devoted to balhimycin biosynthesis, and of phoP, phoR, pstS and phoD, known to be associated to Pi limitation stress response. 2D-Differential Gel Electrophoresis (DIGE) and protein identification, performed by mass spectrometry and computer-assisted 2 D reference-map http://www.unipa.it/ ampuglia/Abal-proteome-maps matching, demonstrated a differential expression for proteins involved in many metabolic pathways or cellular processes, including central carbon and phosphate metabolism. Interestingly, proteins playing a key role in generation of primary metabolism intermediates and cofactors required for balhimycin biosynthesis were upregulated in LP. Finally, a bioinformatic approach showed PHO box-like regulatory elements in the upstream regions of nine differentially expressed genes, among which two were tested by electrophoresis mobility shift assays (EMSA).

Conclusion: In the two chemostat conditions, used to generate biomass for proteomic analysis, mycelia grew with the same rate and with similar glucose-biomass conversion efficiencies. Global gene expression analysis revealed a differential metabolic adaptation, highlighting strategies for energetic supply and biosynthesis of metabolic intermediates required for biomass production and, in LP, for balhimycin biosynthesis. These data, confirming a relationship between primary metabolism and antibiotic production, could be used to increase antibiotic yield both by rational genetic engineering and fermentation processes improvement.

\footnotetext{
* Correspondence: giuseppe.gallo@unipa.it; ampuglia@unipa.it

'Università di Palermo, Dipartimento di Biologia Cellulare e dello Sviluppo,

Viale delle Scienze, Parco d'Orleans II, 90128 Palermo, Italy

Full list of author information is available at the end of the article
} 


\section{Background}

Glycopeptide antibiotics have found a successful use as last resort antibiotics in the treatment of methicillinresistant Staphylococcus aureus (MRSA) infections [1]. Leading glycopeptide drugs are vancomycin and teicoplanin, produced by the actinomycetes Amycolatopsis orientalis and Actinoplanes teichomyceticus, respectively. The actinomycete Amycolatopsis balhimycina DSM5908, which produces the vancomycin-like antibiotic balhimycin [2,3], has been investigated as model strain for studies on glycopeptide biosynthesis since it can be genetically modified and the sequence of bal cluster, containing genes devoted to balhimycin biosynthesis, is available [4-6].

Balhimycin consists of a heptapeptide core made of the proteinogenic amino acids Leu and Asn and the nonproteinogenic amino acids 3,5-dihydroxyphenylglycine (DPG), 4-hydroxyphenylglycine (HPG) and $\beta$ hydroxytyrosine (H-Tyr). This heptapeptide is assembled by a non-ribosomal peptide synthetase (NRPS) and then extensively modified by the so called tailoring reactions, such as oxidative cross-linking of the electron-rich aromatic side chains, halogenation, glycosylation and methylation [6].

In Actinomycetes, the biosynthesis of secondary metabolites like antibiotics is generally elicited as developmental program and physiological response to a variety of environmental stimuli, including high cell density, nutritional limitation and/or presence of stress-inducing agents [7-9]. In A. orientalis [10,11] and A. balhimycina [12] cultivations, performed using minimal defined media, glucose amount was revealed positively correlated with antibiotic biosynthesis, cell growth rate and biomass production. On the other hand, inorganic phosphate $(\mathrm{Pi})$ limitation is known to negatively affect growth rate and biomass production but to be beneficial for the production of glycopeptide antibiotics as shown for vancomycin [10], A40926 (produced by Nonomuraea ATCC 39727) [13] and balhimycin [12]. Pi limitation negatively controls the expression of both primary and secondary metabolism genes [14-16]. In Streptomycetes, $\mathrm{Pi}$-controlled regulatory elements, called PHO boxes, have been reported in the upstream region of Pho regulon genes, which are devoted to Pi-nutritional stress response [15-19]. The PHO boxes are targets of PhoP, a transcriptional regulator whose activity is regulated by the phosphate-sensing membrane protein PhoR. PhoP is reported to have a dual role acting as either positive or negative regulator [16-20]. Although balhimycin biosynthesis has been extensively studied, the molecular bases of limitation of nutrients, such as $\mathrm{Pi}$ and glucose, controlling primary metabolism and antibiotic biosynthesis have not been investigated yet.
Proteomics was proven useful to identify specific biochemical pathways (or parts thereof) and key enzymes to be further targeted in genetic manipulations aimed to maximize the conversion of substrates into useful endproducts in microorganisms $[21,22]$. In this context, we have recently used a differential proteomic approach to demonstrate that balhimycin production in batch culture is associated with the upregulation of enzymes involved in the biosynthesis of antibiotic precursors, thus suggesting that the metabolic apparatus is orientated to sustain balhimycin production $[23,24]$. Accordingly, an increased precursor availability, in particular tyrosine, was recently showed to be beneficial for balhimycin production [25].

Up to date, few experimental studies on antibiotic production have focused attention on continuous cultures, although the advantages of this type of study of microbial physiology have been recognized for many years. In fact, this approach provides useful means of researching the relationships between physiological status of an organism and production of antibiotics by comparing highly reproducible steady-state conditions, where growth parameters (i.e. biomass production yield, growth rate, carbon source uptake, $\mathrm{O}_{2}$ consumption, $\mathrm{CO}_{2}$ and metabolite production) and medium components are constant [10]. In this study, chemostat cultures of $A$. balhimycina were used to obtain steady-state conditions for biomass accumulation with the same growth rate and with or without balhimycin production. These cultivations were then analyzed by a comparative proteomic study to elucidate changes in the expression of genes involved in A. balhimycina primary and secondary metabolism which are associated with biomass production and antibiotic synthesis.

\section{Results and Discussion}

\section{Chemostat cultivation profile}

Preliminary A. balhimycina batch cultivations, performed using a minimal defined medium containing glucose as only carbon source, revealed that to generate 1 $\mathrm{g} / \mathrm{l}$ of biomass dry weight (BDW) about $3 \mathrm{~g} / \mathrm{l}$ of glucose and $0.3 \mathrm{mM}$ of Pi are necessary in a balanced growth. Thus, two minimal defined media, one with low $\mathrm{Pi}$ (0.6 mM; LP) and proficient glucose (12 g/l) concentrations and the other one with high $\mathrm{Pi}(1.8 \mathrm{mM})$ and limiting $(6 \mathrm{~g} / \mathrm{l} ; \mathrm{LG})$ glucose concentrations, were developed to perform $A$. balhimycina chemostat cultivations. Appling a dilution rate of $0.03 \mathrm{~h}^{-1}$ a highly reproducible and stable steady-state was achieved in both conditions (Figure 1: panels A and B), revealing that mycelia grew with the same rate and with a similar biomass production yield, calculated on consumed glucose, i.e. $0.38 \pm$ 0.02 and $0.33 \pm 0.02 \mathrm{~g} / \mathrm{g}$ (BDW/glucose) in LG and LP, 


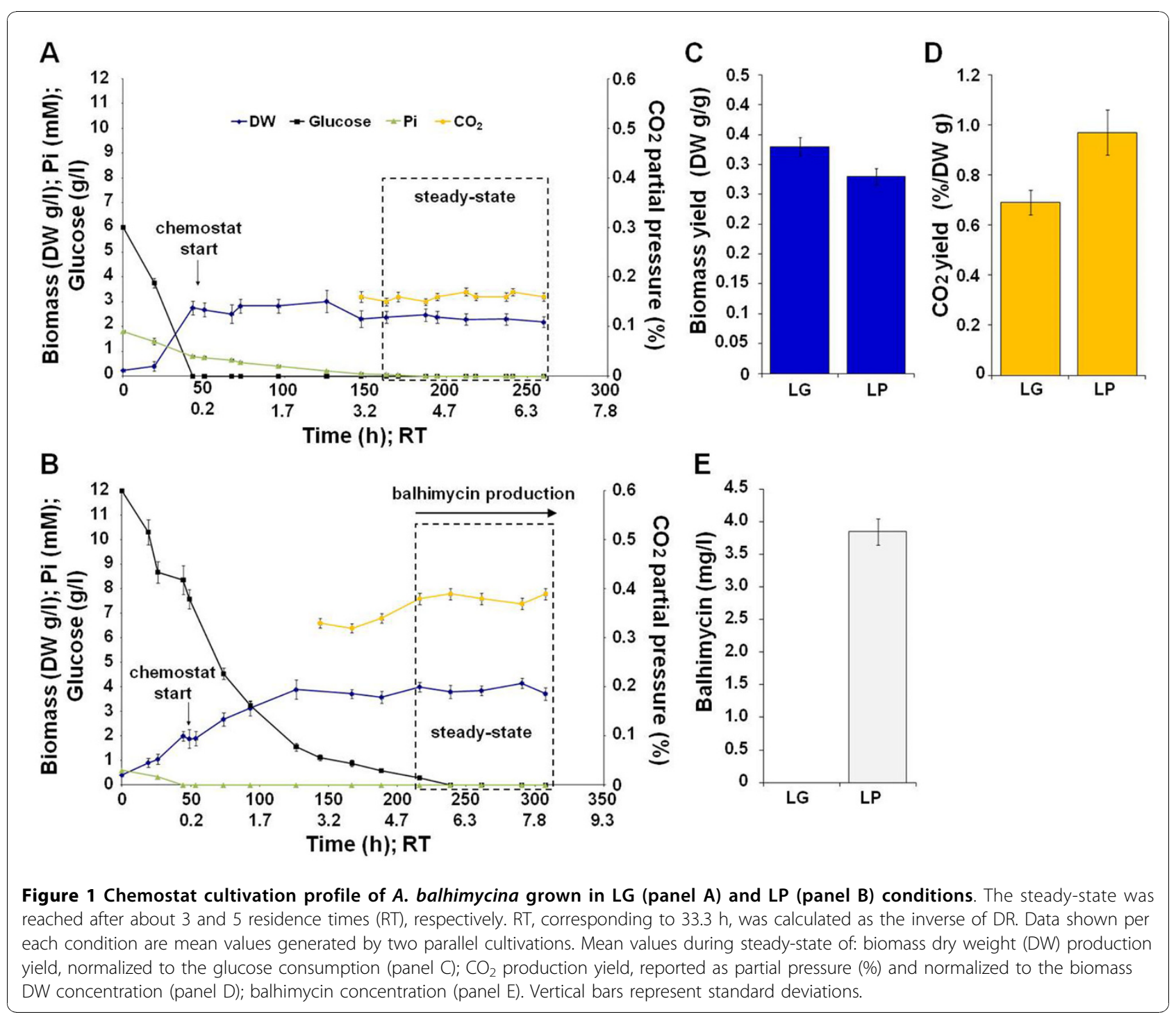

respectively (Figure 1 , panel C). In these systems, residual $\mathrm{Pi}$ and glucose concentrations (Figure 1 panels $\mathrm{A}$ and $\mathrm{B})$ were close to zero during steady-state, thus revealing that glucose and $\mathrm{Pi}$, continuously introduced by feeding in, are completely up-taken during constant growth. Despite the similar glucose-biomass conversion coefficients, $\mathrm{CO}_{2}$ production yield, normalized to BDW, was about 1.4 fold higher in LP than in LG condition Figure 1 panel D). This result indicates an increased metabolism throughout TCA cycle in LP. Interestingly, as demonstrated by HPLC analysis, balhimycin was revealed only in LP condition, showing a productivity of $0.03 \mathrm{mg} / \mathrm{g} / \mathrm{h}$ (balhimycin/BDW/time), and the antibiotic on-set coincided with $\mathrm{CO}_{2}$ production yield increment Figure 1 panel B). Conversely, LG condition resulted in a complete inhibition of antibiotic production. The biomasses, harvested during the steady-state, were then used to carry out gene expression analysis by quantitative (q)RT-PCR of selected genes and by differential proteomic analysis.

\section{Quantitative RT-PCR of Pho regulon genes}

The expression of Pho regulon genes was used as reporter of Pi nutritional stress in chemostat cultures. In Streptomycetes, the products of these genes, like the phosphatase PhoD and the high affinity Pi transporter system PtsSABC, are known to provide extracellular Pi to fulfil the metabolic needs [15-19] or, like the polyphosphate kinase Ppk, to link energetic state of cell and $\mathrm{Pi}$ accumulation [26,27]. A BLAST analysis, performed using amino acid sequence of $S$. coelicolor PhoR, PhoP, PhoD, PstS and Ppk against A. balhimycina ORF database, revealed genes whose products show homology of $65 \%, 90 \%, 67 \%, 59 \%$ and $76 \%$ with their S. coelicolor 
counterparts, respectively. The identification of these $A$. balhimycina proteins was further confirmed by a BLAST analysis, performed using their amino acid sequence (Additional file 1 Table1S) against SwissProt database [28]. In fact, this analysis revealed high degree of homology (ranging from 85 to $100 \%$ ) with actinomycete proteins annotated as PhoP, PhoR, PhoD, PstS and Ppk, respectively (Additional file 1 Table 2S).

As revealed by qRT-PCR, all the tested genes but $p p k$ were upregulated in LP. In particular, phoR and phoP, which also showed co-transcription (data not shown), were induced about 2-fold, while pst $S$ and phoD more than 20-fold (Figure 2). In agreement with RodríguezGarcía and co-workers (2007) that reported upregulation of S. coelicolor homologues [16] in phosphate-deficiency, these data revealed that $\mathrm{Pi}$ is limiting under LP condition.

Surprisingly, $p p k$ expression was downregulated in LP (Figure 2). Ppk is reported to be involved in polyPi utilization in S. lividans [26] or in polyPi synthesis in Bacillus cereus [29] and Myxococcus xanthus [30]. The downregulation of $p p k$ in LP condition suggests that in A. balhimycina the functional role of Ppk is to act mainly as polyPi kinase for Pi storing. In addition, accordingly to that it has already been observed in $S$. lividans [27], the expression of $p p k$ is negatively related to antibiotic production in A. balhimycina.

\section{Quantitative RT-PCR of bal genes}

The expression of selected bal genes, essential for balhimycin production and chosen as representative of polycistronic transcripts [4], was analysed by qRT-PCR. The analysed bal genes are involved in DPG ( $d p g A)$, HPG ( hmaS) and H-Tyr (bpsD) synthesis, in heptapeptide backbone assembling (bpsA) and tailoring reactions (oxy $A$ and $b g t f A)$, as well as in regulatory $(b b r)$ and selfresistance (vanS) mechanisms. qRT-PCR revealed that

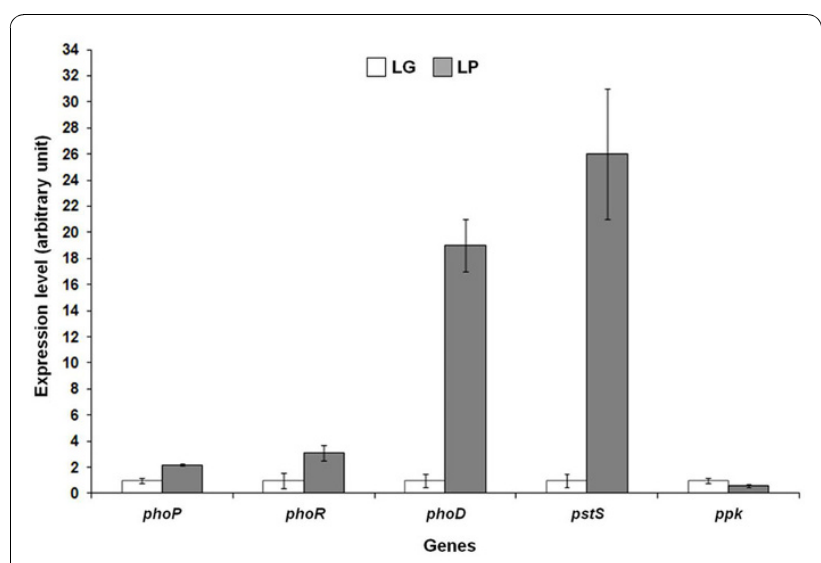

Figure 2 Transcriptional expression profile of selected $A$. balhimycina Pho regulon genes.

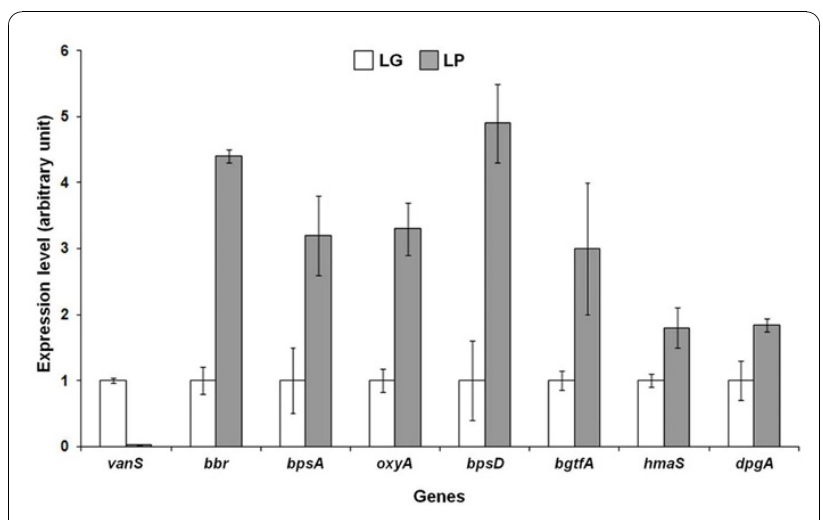

Figure 3 Transcriptional expression profile of selected $A$. balhimycina bal genes.

all these genes are upregulated under LP condition (Figure 3), with the exception of vanS, thus revealing that the Pi limitation in glucose proficiency positively affects the expression of balhimycin biosynthetic genes. VanS is a membrane protein acting with the transcriptional regulator VanR as a two-component system putatively devoted to sense extracellular balhimycin. Its downregulation is in agreement with the mechanism proposed by Walsh et al. [31] where VanR negatively controls the expression of vanSR bicistronic transcript in the presence of glycopeptide antibiotics.

Under LG condition, the low expression levels of bal genes could not explain alone the absence of antibiotic production. In fact, this finding suggests complex regulatory mechanisms involving the synthesis of balhimycin precursors and the formation of the end-product. The importance of the availability of precursors in antibiotic biosynthesis will be elucidated by proteomic results.

\section{Proteomic analysis}

Analysis of global protein expression changes between LP and LG conditions was performed by 2D-Differential Gel Electrophoresis (2D-DIGE) analysis (Figure 4). This investigation revealed 72 upregulated and 12 downregulated protein spots in LP condition, showing at least 1.5 fold increased or decreased abundance (calculated as spot Vol) and at least a probability for null hypothesis (p) $<0.05$ (calculated using the analysis of variance or ANOVA test). These proteins were identified by MS analysis or by automatic gel-matching using the $A$. balhimycina protein $2 \mathrm{D}$ reference-maps, available over the World Wide Web as interactive pages at http://www. unipa.it/ampuglia/Abal-proteome-maps[23,24] (Additional file 1 Table $3 \mathrm{~S}, 4 \mathrm{~S}, 5 \mathrm{~S}$ and $6 \mathrm{~S}$ ). The reliability of this analysis was firstly demonstrated by the identification of groups of proteins showing similar expression profiles and whose corresponding genes are arranged in putative operons (Additional file 1 Table 6S), which are 


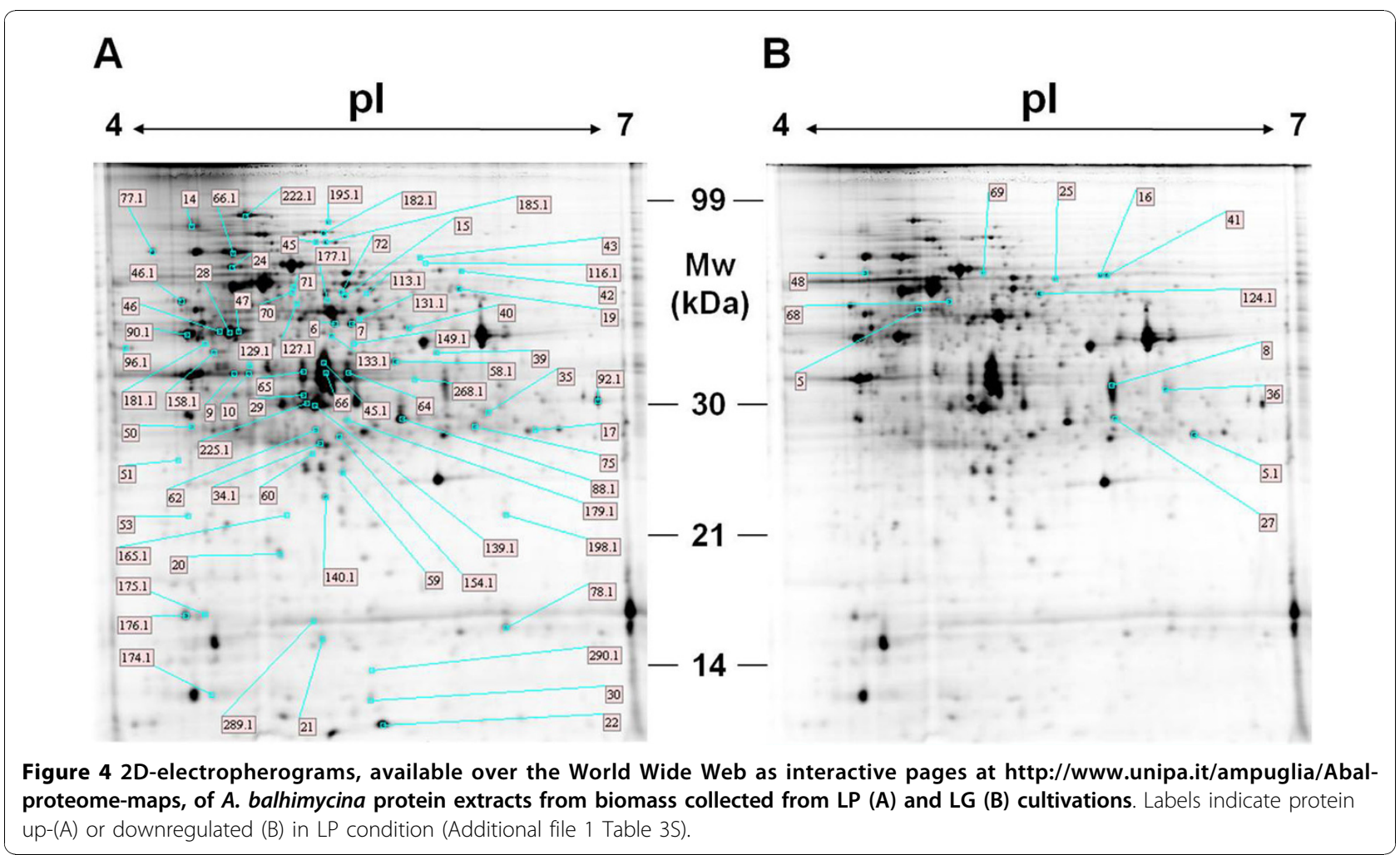

characterized by a maximum of $60 \mathrm{bp}$ between two adjacent ORFs. The identified proteins were clustered into functional categories according to BioCyc http:// biocyc.org/[32], KEGG http://www.genome.jp/kegg/[33] and ExPASy http://expasy.org/[28] metabolic databases. The functional clustering revealed that the differentially expressed proteins are related to many metabolic pathways or cellular processes, including glucose and phosphate metabolism. On the basis of their function, the identified proteins could be divided in several groups which are related to central carbon metabolism (31\%), protein biosynthesis/amino acid metabolism (21\%), redox and energetic balance (10\%), nucleotide/fatty acid/ amino sugar metabolism (10\%) and balhimycin biosynthesis $(2 \%)$ or are unknown $(15 \%)$. The role of these proteins is discussed below in dedicated sections, highlighting the mechanisms controlling adaptation to $\mathrm{Pi}$ limitation, glucose catabolism and the metabolic strategies aimed to ensure metabolic intermediates for both biomass accumulation and antibiotic biosynthesis.

\section{Central carbon catabolism}

Most differentially expressed proteins are involved in glycolysis, pentose phosphate pathway (PPP), and TCA cycle (Figure 5; Additional file 1 Table 3S). In particular, glycolytic enzymes glucose-6-phosphate isomerase (PgiA), triosephosphate isomerase (TPI), phosphoglycerate kinase (Pgk), glyceraldehyde 3-phosphate dehydrogenase
(GAPDH), fructose-bisphosphate aldolase (FDA), PPdependent-fructose 6-phosphate 1-phosphotransferase (P-PFK), enolase (ENO) and pyruvate dehydrogenase complex members (two dihydrolipoamide dehydrogenases, LpdA1 and 2, and one dihydrolipoamide acyltransferase, SucB) were upregulated in LP condition. The upregulation of these enzymes suggests an increased metabolic flux throughout glycolysis. This result is in agreement with the upregulation of the enzymes transketolase $(\operatorname{Tr} K)$ and transaldolase $(\operatorname{Tr} \mathrm{A})$, both belonging to non-oxidative branch of PPP, since these enzymes use as substrates the glycolytic intermediates fructose-6P and glyceraldehyde-3P, respectively. In addition, also the enzyme F420-dependent glucose-6-phosphate dehydrogenase (G6PD) was upregulated in LP, thus suggesting an increased flux throughout the oxidative branch of PPP as well. The upregulation of glycolytic enzymes is also in agreement with the upregulation of TCA cycle enzymes aconitate hydratase (ACO), succinate dehydrogenase flavoprotein subunit (SudA), LpdA1 and 2, SucB, succinylCoA ligase alpha and beta subunit (A-and B-SCS) and malate dehydrogenase (MDH) (Figure 5; Additional file 1 Table 3S). These findings also correlated with the increased production yield of $\mathrm{CO}_{2}$ in LP condition (Figure 1D) and also with the upregulation of ThiS and ThiC, involved in thiamine synthesis and previously associated with balhimycin production [23]. Thiamine diphosphate (TDP) is reported to be a co-factor of the 


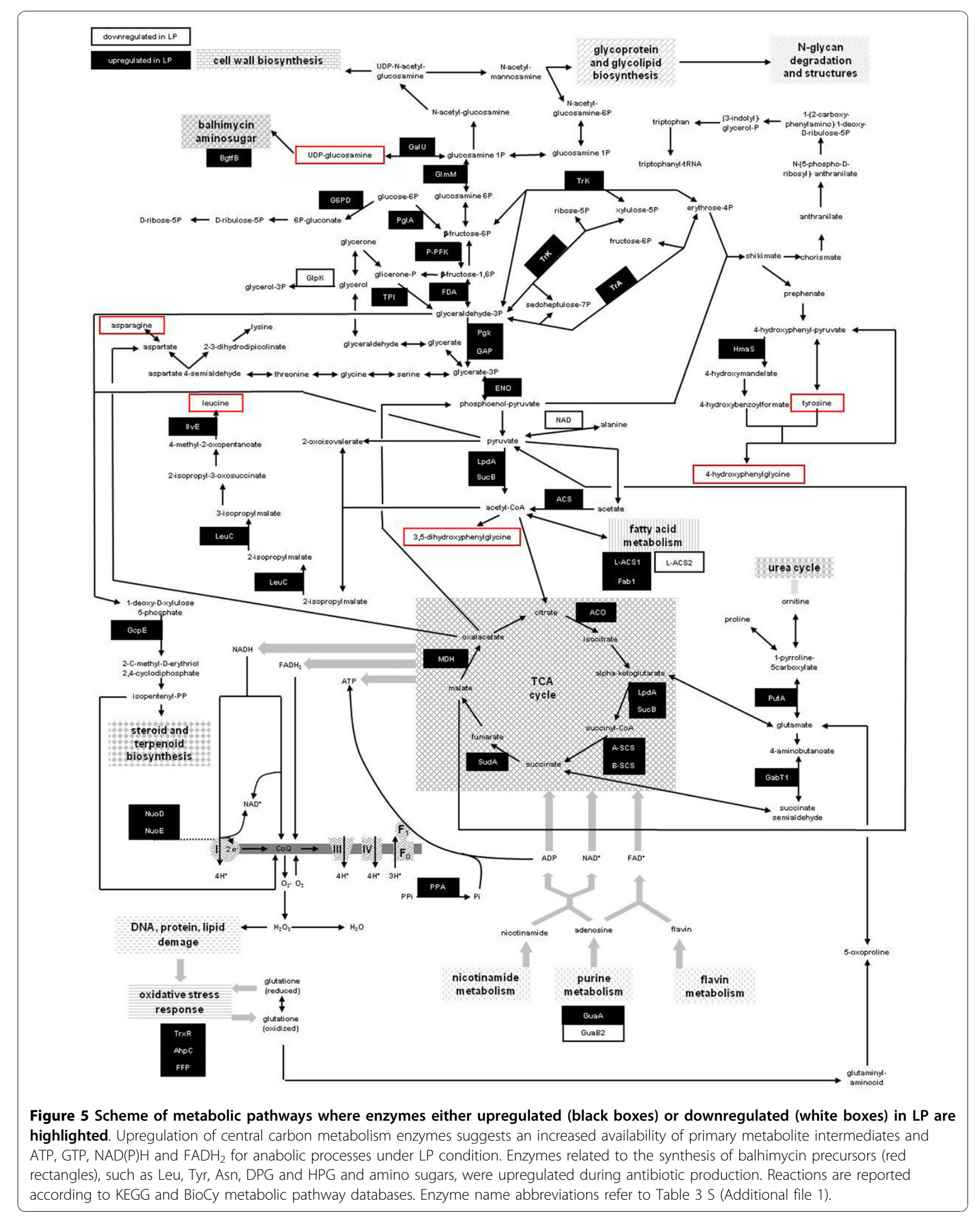


upregulated TrK, pyruvate and alpha-ketoglutarate dehydrogenase complexes [34]. Finally, an ABC transport system ATPase component and an extracellular sugarbinding protein resulted downregulated in LP. These two proteins share conserved domains with LivG/F ATPases and MalE, respectively, which are shown to be required for the up-take of alternative carbon sources during glucose limitation/starvation $[35,36]$.

The importance of glycolysis [37] and TCA cycle [10,16,38-40] for energetic balance and antibiotic production in Actinomycetes has already been reported. The upregulation of central carbon metabolism enzymes leads to an increased availability of $\mathrm{NAD}(\mathrm{P}) \mathrm{H}, \mathrm{FADH}_{2}$, GTP and ATP and of primary metabolism intermediates. In fact, pyruvate and acetyl-CoA, from glycolysis, erytrose-4P, from PPP, and alpha-ketoacids from TCA cycle are required for anabolic routes such as amino acid biosynthesis (Figure 5). Interestingly, the upregulation of central carbon metabolism enzymes does not result in an increased biomass production yield, calculated on glucose consumption, in LP (Figure 1C). This result is most probably due to Pi limitation that negatively affects growth. On the contrary, the Pi proficiency in LG is counterbalanced by the low glucose availability that results in downregulation of central carbon metabolism enzymes. Thus, the similar biomass production yield in LP and LG conditions is achieved throughout a differential expression of central carbon metabolism key enzymes that provides for metabolic adaptation to energetic imbalance due to Pi limitation in LP condition and leads to an increased synthesis of primary metabolism intermediates and cofactors eventually required for biomass production and for balhimycin biosynthesis.

\section{Fatty acid metabolism}

Two long-chain-fatty-acid-CoA ligases, namely L-ACS1 and 2, were upregulated and downregulated in LP, respectively (Figure 5; Additional file 1 Table 3S). Both are involved in the reversible formation of an acyl-carrier protein in the metabolism of fatty acids, with a mechanism leading to the release of PPi from ATP. In addition, the enzyme enoyl-ACP reductase (FabI), catalyzing the formation of trans-2,3-dehydroacyl-[acyl-carrier protein] and $\mathrm{NADH}$ from $\mathrm{NAD}^{+}$and enoyl-acyl[acyl-carrier-protein] C4-16 derivatives, was upregulated in LP. This result is in agreement to Summers et al., (1999) [41] that revealed fabI being part of an operon induced in Pi limited cultures of Sinorhizobium meliloti. The downregulation of the glycerol kinase (GlpK) catalyzing glycerol phosphorylation, suggests a decreased synthesis of glycerolipids due to Pi limitation, which, instead, could be used as phosphorous source, as it has already been observed in Bacillus subtilis [42].

\section{Oxidative stress and hypothetical proteins}

In agreement with the increased expression of TCA cycle enzymes, some upregulated proteins are involved in oxidative phosphorylation or counterbalance reactive oxidative species (ROS) generation and damage. In fact, upregulation was revealed for NADH:ubiquinone oxidoreductase proteins (NuoE and NuoD), 4-hydroxy-3methylbut-2-en-1-yl diphosphate synthase (GcpE), involved in the synthesis of isopentenyl-PP that is a precursor of CoQ, AhpC, a thiol-specific antioxidant protein using reducing equivalents derived from either thioredoxin (TrxR) and glutathione, and TrxR, a small protein that alters the redox state of target proteins through the reversible oxidation of its active site (Figure 5; Additional file 1 Table 3S). These results are also in agreement with the increment of oxidative stress that has been already observed in $E$ coli during Pi starvation [43]. In addition, upregulation of ferritin family protein (FFP) is in agreement with that it has already been observed in S. coelicolor [16] and in S. meliloti [44] and with a possible role in free iron detoxification for protection against ROS [45].

Hypothetical proteins (Additional file 1 Table 3S) that were previously associated with balhimycin production [23], such as a forkhead associated domain containing protein (FDCP) and a MoxR-domain containing ATPase, were also up-regulated in LP [46].

\section{Protein biosynthesis and nucleic acid metabolism}

A number of proteins related to protein biosynthesis or protein folding and stress-damage response resulted upregulated in LP (Additional file 1 Table 3S). This is the case of elongation factor $\mathrm{Tu}(\mathrm{EF}-\mathrm{Tu})$, trigger factor (TF), peptidyl-prolyl cis-trans isomerase (PPI), a cold shock-like protein (CSP-G), chaperone protein DnaK and Clp protease ATP-binding subunit (ClpB). In contrast, $60 \mathrm{kDa}$ chaperonin GroEL and $30 \mathrm{~S}$ ribosomal protein S1 RpsA were downregulated under LP conditions (Additional file 1 Table 3S), as reported also in $S$. coelicolor [16], in B. subtilis [42] and in S. meliloti [44] incubated in Pi limiting condition. This result correlates with the chemostat cultivation conditions used, where mycelia are in a proliferating state and in LP a pool of upregulated factors, required for protein biosynthesis, may need to counterbalance energetic stress due to Pi limitation. In fact, the upregulation of factors necessary for either ribosomal activity or for protein folding together with the concomitant downregulation of the ribosomal protein RpsA, the largest ribosomal component with a pivotal role in ribosome assembly [47], may reflect the need to optimize the efficiency of protein biosynthesis under $\mathrm{Pi}$ nutritional stress conditions. 
Under Pi limitation, bacteria may reduce their nucleoside pool [16] and accordingly inosine 5'-phosphate dehydrogenase (IMPDH), whose activity is required for the biosynthesis of xanthosine-5'P, a precursor of both guanosine and adenosine [48], was downregulated in LP. Surprisingly, guanosine 5'-phosphate (GMP) synthase, whose activity is associated with the formation of GMP and PPi from xantosine-5'P, was instead upregulated LP. This result might be explained since, as shown in KEGG pathway database, GMP synthase substrate (xanthosine$\left.5^{\prime} \mathrm{P}\right)$ could derive from biochemical routes involving a pool of xantine and xantosine-triP or-tetraPi, in a salvage pathway that could be activated in Pi limitation.

\section{Balhimycin production}

The amino acids H-Tyr, HPG, DPG, Asn and Leu are necessary to form the balhimycin heptapeptide backbone. Their availability from primary metabolism pathways is crucial for antibiotic biosynthesis [25]. Nonproteinogenic amino acids $\mathrm{H}-\mathrm{Tyr}$ and HPG are also derived from metabolism of Tyr, which is also the amino donor during DPG biosynthesis. Genes encoding enzymes involved in the last steps of H-Tyr, HPG and DPG biosynthesis are present in the bal cluster, which also contain genes coding for enzymes required in the metabolism of amino sugars, essential for antibiotic glycosylation.

In agreement with balhimycin production observed only in LP, primary and secondary metabolism enzymes involved in the biosynthesis of balhimycin precursors, such as amino acids and amino sugars resulted upregulated in LP condition. In particular, the metabolic building blocks pyruvate, acetyl-CoA, oxalacetate, $4 \mathrm{P}$-erythrose and glucose-6P from central carbon metabolism are required for Leu, DPG, Asn, Tyr, HPG and amino sugar biosynthesis, respectively (Figure 5) [25]. Thus, bal gene product HmaS-involved in HPG synthesis and whose expression was revealed upregulated by qRT-PCR-, 3-isopropylmalate dehydratase large subunit (LeuC) and branched-chain amino acid aminotransferase (IlvE)-catalyzing different reactions in Leu biosynthesis-, $\mathrm{MDH}$-catalyzing biosynthesis of Asp-precursor oxalacetate-, bal gene product Bgtf, phosphoglucosamine mutase (GlmM) and UTP-glucose-1-phosphate uridylyltransferase (GalU)-required in the metabolism of amino sugars-were upregulated in LP. GlmM is particularly interesting because it catalyzes the formation of glucosamine-1P, a metabolic intermediate that is converted into UDP-glucosamine from GalU (Figure 5; Additional file 1 Table 3S). UDP-glucosamine is reported to be likely the primary metabolism building block required for the biosynthesis of modified amino sugars in glycopeptide teicoplanin, chloroeremomycin, and balhimycin [49]. Interestingly, a 4-phosphopantetheinyl transferase (PPT) was upregulated in LP. PPTs form a superfamily of enzymes that transfer prosthetic 4-phosphopantetheine moiety from CoA to carrier domain of biosynthetic complexes required for the synthesis of a wide range of compounds including fatty acid, polyketide (PK) and nonribosomal peptide (NRP) metabolites. As revealed by BLAST analysis, A. balhimycina PPT possesses conserved domains characteristic of Sfp-like phosphopantetheinyl transferases family. Members of this family are mainly found associated either with NRP synthetase and PK synthase [50]. Thus, even if an involvement in fatty acid biosynthesis could not be totally excluded, PPT might likely be involved in both balhimycin heptapeptide assembly line and in the synthesis of DPG, a polyketide derivative, synthesized by $\operatorname{dpg} A B C D$ products [51].

Altogether, these data suggest that the destination of metabolic intermediates in LP and LG cultivations is differentially regulated. In particular, the increment of glucose catabolism in LP condition is coupled with the synthesis of metabolic building blocks related to the generation of both balhimycin backbone and amino sugar moieties.

\section{Identification of PHO box regulatory elements in the upstream of differentially expressed genes}

Global gene expression analysis was proven as a good starting point to identify common regulatory elements, such as PHO boxes, in the upstream region of differentially expressed genes in S. coelicolor [16]. Similarly, putative $\mathrm{PHO}$ box regulatory elements, upstream the translational start site of differentially expressed genes, were searched by sequence homology using published $S$. coelicolor PHO box consensus [18]. Thus, PHO box directed repeats (DRs) in the upstream region of the genes encoding PstS, Ppk, PhoD, MDH, B-SCS, HmaS, Gabt1, LpdA2 and P-PFK were revealed by bioinformatics (Additional file 1 Table 7S and 8S). The consensus of $A$. balhimycina DRs (Figure 6), created using free-on line available WebLogo software http://weblogo.

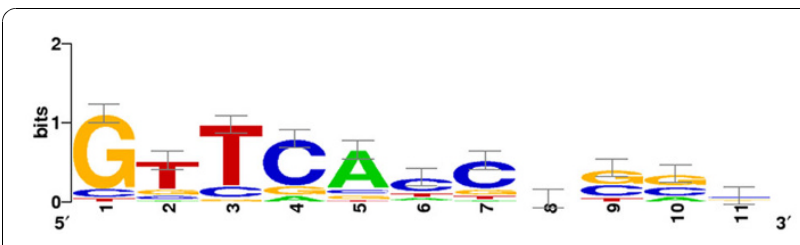

Figure 6 Consensus of the direct repeats of $11 \mathrm{nt}$ that forms the $\boldsymbol{A}$. balhimycina PHO box. This logo corresponds to a model that comprises 19-DRs from nine A. balhimycina genes (Additional file 1 Tables $6 S$ and $7 S$ ). The height of each letter is proportional to the frequency of the base; the height of the letter stack is the conservation in bits at that position. Error bars are shown at the top of the stacks. 
berkeley.edu/logo.cgi[52], shows high similarity with that of $S$. coelicolor revealing a high conservation of the first seven positions [18].

Experimental validation was carried out by electrophoresis mobility shift assay (EMSA) for the putative PHO boxes in the upstream of $p s t S$ and $p p k$, which were up-and downregulated in LP respectively, as revealed by qRT-PCR. In particular, 40 and 38 bp DNA fragments containing the upstream regions of $A$. balhimycina pstS (PpstS Amy) and ppk (Pppk Amy), respectively, and A. balhimycina crude extracts from biomass generated in LP condition were used. This analysis showed that both PpstS Amy and Pppk Amy specifically bind to the crude extract (Figure 7). Notably, a $40 \mathrm{bp}$ DNA fragment containing the PHO box of pstS from $S$. coelicolor (PpstS Sco) specifically competed to A. balhimycina crude extract bound, resulting in reduction of band shift intensity for both PpstS Amy and Pppk Amy. This result, revealing an interspecific competition between $S$. coelicolor and A. balhimycina PHO boxes, suggests the binding of PhoP to these A. balhimycina regulatory DNA elements. The presence of a PHO box in the upstream region of both up-and downregulated genes is in agreement with PhoP dual role as positive or negative regulator [17-20]. Even if the expression of $p p k$ is positively and indirectly controlled by PhoP in S. lividans TK24 [26], it is neither PhoP-or Pi-controlled in $S$. coelicolor [16]. Instead, in A. balhimycina the putative PHO box in the upstream region of $p p k$ could be explained by a negative control of PhoP over $p p k$ expression.

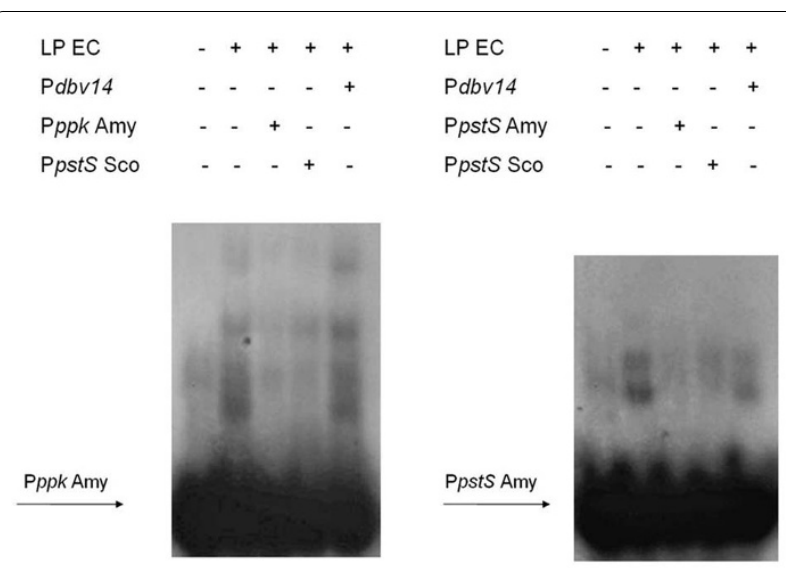

Figure $7 \mathrm{Gel}$ band shift assays. EMSA was carried out using DNA fragments upstream A. balhimycina ppk (Pppk Amy) and pstS (PpstS Amy) and a crude extract from A. balhimycina LP culture. The use of a molar excess (200 fold) of unlabeled probe as well as of a DNA fragment upstream S. coelicolor pstS (PpstS Sco), containing a PHO box, reduced the band shift signals for both probes. No reduction of band shift signals is visible using a molar excess (200 fold) of an unspecific competitor (Nonomuraea Pdbv14 [14]).
Thus, the presence of PHO box regulatory elements in the upstream of differentially expressed genes suggests a PhoP-mediated mechanism for the regulation of their expression. Anyway, further investigations, such as the construction of a $A$. balhimycina $\Delta p h o P$ strains and EMSAs carried out with a purified A. balhimycina PhoP, should be performed to better clarify the role of PHO box-like regulatory elements in controlling the expression of A. balhimycina genes in Pi limitation.

\section{Conclusions}

This is the first report describing a differential proteomic analysis for a glycopeptide producer strain incubated in continuous cultivations. Comparative analyses of global expression profiles in non-producing and producing conditions in batch cultivations may be affected by growth rate and changes of medium component concentrations. In the chemostat conditions which were set-up in this study to compare A. balhimycina proteomes in producing and non producing conditions, mycelia grew with the same rate and with similar glucose-biomass conversion coefficients.

Both transcriptional and proteomic analyses highlighted that in LP and LG conditions energy balance and generation of primary metabolism intermediates are mainly regulated by controlling the expression of central carbon metabolism enzymes and proteins, such as PstS, PhoD and an inorganic pyrophosphatase (PPA), whose activity is required for Pi recovering. The upregulation in LP of central carbon metabolism genes does not result in an increased biomass production yield on glucose consumption. Instead, the upregulation of catabolic and anabolic enzymes, coupled with the upregulation of bal genes, accounts for the supply of cofactors and precursors, such as amino acids and/or amino sugars, that otherwise could eventually become limiting for balhimycin biosynthesis.

Altogether these data correlate with the fact that in Actinomycetes secondary metabolites are generally synthesized through multiple intracellular reactions, which are further affected by cofactor balance and regulatory circuits at different levels of cellular metabolism [53-55]. Thus, altogether these data could be used to redesign fermentation strategies that are difficult to be intuitively identified and for approaching the prediction of new genetic targets from primary metabolism genes to be engineered for a rational construction of antibiotic high-yielding producer strains.

\section{Materials and methods}

\section{Strain and culture condition}

The A. balhimycina DSM5908 strain used in this work was a gift from Prof. Wohlleben, University of Tubingen, Germany. The strain was stored in 1-ml cryotubes 
at $-80^{\circ} \mathrm{C}$ in $15 \%$ glycerol and $8 \mathrm{~g} / \mathrm{l}$ tryptic soy broth (Difco, Detroit, Mich.), at a biomass dry weight of approximately $0.2 \mathrm{~g} / \mathrm{ml}$. For seed culture preparations, a 250-ml baffled Erlenmeyer flask containing $50 \mathrm{ml}$ of tryptic soy broth (Difco) was inoculated with one glycerol stock vial and incubated with shaking $(150 \mathrm{rpm})$ at $30^{\circ} \mathrm{C}$. After $48 \mathrm{~h}$ of incubation, this seed culture was used for inoculation of the fermentors $(5 \% \mathrm{v} / \mathrm{v})$. The fermentations were performed in $1 \mathrm{l}$ double-jacketed Applikon fermentors (Applikon, Shiedam, Netherlands) containing $1 \mathrm{l}$ medium with an agitation rate of 500 $\mathrm{rpm}$ and aeration at $1 \mathrm{vvm}$ (air volume/working volume $/ \mathrm{min}$ ). Dissolved $\mathrm{O}_{2}$ tension was monitored with an $\mathrm{O}_{2}$ electrode (Mettler Toledo, Greifensee, Switzerland); it did not fall below $50 \%$ saturation during any of the fermentations. The $\mathrm{pH}$ was kept at a value of 7.0 by addition of $1 \mathrm{M} \mathrm{NaOH}$; temperature was maintained at $30^{\circ} \mathrm{C}$. The two fermentation media, named LG and LP for low glucose and phosphate, respectively, contained the compounds in the concentration reported in Additional file 1 Table 9S. LP and LG chemostat experiments were performed in two parallel replicates, respectively, using a constant dilution rate (DR) of $0.03 \mathrm{~h}^{-1}$. It took about 3 and 5 residence times (RT, calculated as the inverse of DR) to achieve the stabilization of growth parameters (steady-state) in LG and LP cultivations which was confirmed by the constant off-gas and biomass concentration. The biomass samples used for total protein and RNA extractions were harvested during steady-state after about 6.7 and 7.9 RT from LG and LP cultivations, respectively, and immediately frozen in liquid $\mathrm{N}_{2}$ and then stored at $-80^{\circ} \mathrm{C}$.

\section{Analysis of biomass dry weight}

For biomass concentration, sampling was performed manually in triplicate from each cultivation. The optical density was measured on a UV-vis spectrophotometer UV mini 1240 from Shimadzu at $600 \mathrm{~nm}$. For dry weight measurements, $3 \mathrm{ml}$ samples were filtered through a pre-weight $45 \mathrm{~mm}$ pore size Sartorius filter and washed with $0.9 \% \mathrm{NaCl}(\mathrm{w} / \mathrm{w})$. The filters (with content) were dried $20 \mathrm{~min}$ at $150 \mathrm{~W}$ in a microwave oven and weighted after cooling.

\section{Analysis of glucose and phosphorus utilization}

Glucose concentration in spent medium was measured by high performance liquid chromatography (HPLC) (Agilent Technologies, Palo Alto, $\mathrm{CA}$ ) equipped with an AMINEX HPX-87 H column (Bio-Rad Laboratories, Hercules, CA) working at 60 1C. $5 \mathrm{mM} \mathrm{H}_{2} \mathrm{SO}_{4}$ was used as mobile phase with a flow rate of $0.6 \mathrm{ml} \mathrm{min}^{-1}$. Standard UV index detection at $210 \mathrm{~nm}$ was used for quantification.
Phosphorus concentration in spent medium was analyzed using a spectrophotometric assay kit (Inorganic phosphorus 80; Abx Diagnostics, Montpellier, France) in an automatic analyzer (Cobas Miras plus; Roche, Basel, Switzerland).

\section{Analysis of $\mathrm{CO}_{2}$ in exhaust gas}

The partial pressure of $\mathrm{CO}_{2}$ in the exhaust gas from the bioreactors was measured using a gas analyzer (Industrial emission monitor type 1311; Brüel \& Kjaer, Denmark).

\section{Analysis of balhimycin}

Balhimycin titers in the cultivations were detected and quantified using liquid chromatography mass spectrometry (LCMS) as described elsewhere [25]. LC-DADESI+-MS data were acquired on an Agilent 1100 HPLC system (Agilent Technologies, Waldbronn, Germany) equipped with a diode array detector scanner. The HPLC system was connected to an Agilent MSD Ion trap operated in positive electrospray full scan mode (m/z 100-1500) with 4 scans per second. The amount of balhimycin was quantified using UV detection at 195 and $280 \mathrm{~nm}$ and calculated using a standard curve. Separation was done on a Phenomenex Gemini C18 110A column $\left(2 \times 100 \mathrm{~mm}^{2}, 3 \mu \mathrm{m}\right)$ with a flow rate of $0.3 \mathrm{ml} / \mathrm{min}$ at $40^{\circ} \mathrm{C}$ using water $(\mathrm{pH} 10.5$ with $10 \mathrm{mM}$ ammonium formate) and methanol solution in the following gradient: $\mathrm{t}=0 \mathrm{~min}, 10 \%$ methanol; $\mathrm{t}=24 \mathrm{~min}$, $100 \%$ methanol; $\mathrm{t}=30 \mathrm{~min}, 10 \%$ methanol.

\section{Protein extraction and separation for 2D-Differential Gel Electrophoresis (2D-DIGE) analysis}

Frozen biomass samples, collected from two parallel cultivations for each condition, were sonicated in non reducing conditions using experimental procedures as previously described [23]. After dialysis against distilled water, at $4{ }^{\circ} \mathrm{C}$, and acetone precipitation at $-20^{\circ} \mathrm{C}$, proteins were dissolved in the appropriate 2D-DIGE lysis buffer (30 mM Tris, $7 \mathrm{M}$ urea, $2 \mathrm{M}$ thiourea, 4\% CHAPS).The four protein extracts (one for each replica per each condition) were analyzed in two technical replicates. In particular, two $40 \mu \mathrm{g}$ protein aliquots from each extraction were minimally labelled using 320 pmol Cy3 and 320 pmol Cy5 fluorescent dyes (CyDye ${ }^{\mathrm{mm}}$ DIGE minimal labelling kit, GE Healthcare, Uppsala, Sweden), respectively, to account for florescence bias. Labelling reactions were carried out in the dark on ice for $30 \mathrm{~min}$. and quenched with $0.2 \mathrm{mM}$ lysine, according to manufacturer instructions. In addition, four $40 \mu \mathrm{g}$ protein aliquots from a standard pool, generated by combining an equal amount of all the four protein extracts, were minimally labelled with 320 pmol Cy2 fluorescent dye (CyDye ${ }^{\mathrm{mm}}$ DIGE, GE 
Healthcare) according to manufacturer instructions. To perform 2D-DIGE analysis, $40 \mu \mathrm{g}$ of LG and LP labelled proteins were mixed, combining $\mathrm{Cy} 3$ and $\mathrm{Cy} 5$ fluorescent dyes, with the addition of $40 \mu \mathrm{g}$ of internal standard Cy2labelled proteins, thus generating a total of four protein mixes.

For isoelectrofocusing (IEF), DeStreak rehydration solution (GE Healthcare) containing 0.5\% (v/v) IPG buffer (GE Healthcare) and 1\% (w/v) DTE (Sigma) was added to each mix up to $340 \mu \mathrm{l}$ (final volume). IEF was performed as previously described [23] using 4-7 pH range $18 \mathrm{~cm}$-IPG strips (GE Healthcare) in an Ettan IPGphor III apparatus (GE Healthcare). The focused proteins were then separated using $12 \%$ sodium dodecyl polyacrylamide gels (SDS-PAGE) at $10^{\circ} \mathrm{C}$ in a Hettan Dalt six (GE Healthcare), with a maximum setting of 40 $\mu \mathrm{A}$ and $110 \mathrm{~V}$ per gel.

The four 2D-Gels were scanned with a DIGE imager (GE Healthcare) to detect cyanin-labeled proteins according to manufacturer's instructions. Differential gel analysis was performed automatically using Image Master 2D Platinum 7.0 DIGE software (GE Healthcare), according to the manufacturer's instructions. Protein spots were detected automatically and manually verified. Individual spot abundance was automatically calculated from the quadruplicated 2D-Gels as mean spot volume (Vol, i.e. integration of optical density over spot area) and normalized to the Cy2-labeled internal pooled standard. Protein spots showing more than 1.5 fold change in Vol, with a statistically significant ANOVA value ( $\mathrm{p}<$ 0.05 ), were considered differentially abundant and identified as described in the following section by either MS analysis or by gel-matching procedures using $A$. balhimycina protein $2 \mathrm{D}$ reference-maps previously obtained $[23,24]$.

\section{MS analysis and protein identification}

Protein spots were excised from the 2D-Gels, alkylated, digested with trypsin and identified as previously reported [23]. Peptide mixtures were desalted by $\mu$ ZipTipC18 (Millipore, MA) using 50\% (v/v) acetonitrile/5\% (v/v) formic acid as eluent before MALDI-TOF-MS and/or nLC-ESI-LIT-MS/MS analysis.

In the case of MALDI-TOF-MS experiments, peptide mixtures were loaded on the MALDI target, using the dried droplet technique and $\alpha$-cyano-4-hydroxycinnamic acid as matrix, and analyzed using a Voyager-DE PRO mass spectrometer (Applied Biosystems, USA) operating in positive ion reflectron, with an acceleration voltage of $20 \mathrm{kV}$, a nitrogen laser $(337 \mathrm{~nm})$ and a laser repetition rate of $4 \mathrm{~Hz}$ [56]. The final mass spectra, measured over a mass range of 700-6000 Da and by averaging 400-800 laser shots, were elaborated using the DataExplorer 5.1 software (Applied Biosystems) and manually inspected to get the corresponding peak lists. Internal mass calibration was performed with peptides deriving from trypsin autoproteolysis.

Tryptic digests were eventually analyzed by nLC-ESILIT-MS/MS using a LTQ XL mass spectrometer (ThermoFisher, San Jose, CA) equipped with a Proxeon nanospray source connected to an Easy-nanoLC (Proxeon, Odense, Denmark) [57]. Peptide mixtures were separated on an Easy $\mathrm{C}_{18}$ column $(10 \times 0.075 \mathrm{~mm}, 3$ $\mu \mathrm{m})$ (Proxeon). Mobile phases were $0.1 \%$ (v/v) aqueous formic acid (solvent A) and $0.1 \%(\mathrm{v} / \mathrm{v})$ formic acid in acetonitrile (solvent B), running at total flow rate of 300 $\mathrm{nL} / \mathrm{min}$. Linear gradient was initiated $20 \mathrm{~min}$ after sample loading; solvent B ramped from $5 \%$ to $35 \%$ over 45 min, from $35 \%$ to $60 \%$ over $10 \mathrm{~min}$, and from $60 \%$ to $95 \%$ over $20 \mathrm{~min}$. Spectra were acquired in the range $\mathrm{m} / \mathrm{z}$ 400-2000. Acquisition was controlled by a datadependent product ion scanning procedure over the three most abundant ions, enabling dynamic exclusion (repeat count 2 and exclusion duration $60 \mathrm{~s}$ ); the mass isolation window and collision energy were set to $m / z 3$ and $35 \%$, respectively.

MASCOT search engine version 2.2.06 (Matrix Science, UK) was used to identify protein spots unambiguously from an updated NCBI nonredundant database also containing the $A$. balhimycina ORF product database based on A. balhimycina DSM5908 genome sequencing [23] by using MALDI-TOF-MS data, a mass tolerance value of 40-80 ppm, trypsin as proteolytic enzyme, a missed cleavages maximum value of 2 and Cys carbamidomethylation and Met oxidation as fixed and variable modification, respectively. Candidates with a MASCOT score $>83$ (corresponding to $\mathrm{p}<0.05$ for a significant identification) were further evaluated by the comparison with their calculated mass and pI values, using the experimental values obtained from 2-DE.

Raw data files from nLC-ESI-LIT-MS/MS experiments were searched with SEQUEST (ThermoFisher Scientific, USA) within the Proteome Discoverer software package (Thermo Fisher Scientific, San Jose, CA, USA, version 1.0 SP1) against the NCBI nonredundant database implemented by the preliminary version of the A. balhimycina DSM5908 ORF product database mentioned above [23]. Database searching was performed by selecting Cys carbamidomethylation as a fixed modification and Met oxidation as variable modification. Searches were carried out by using a mass tolerance value of 2.0 Da for precursor ion and 0.8 Da for MS/MS fragments, trypsin as proteolytic enzyme, a missed cleavages maximum value of 2 . Other SEQUEST parameters were kept as default. Candidates with more than 2 assigned peptides with an individual SEQUEST score versus charge state $>1.5$ for charged state (CS) $1,>2.0$ for CS 2, > 2.4 for CS 3, > 3.3 for CS $4,>4.2$ for CS 5 , > 4.5 for CS 6 
were considered confidently identified. Definitive peptide assignment was always associated to manual spectral visualization and verification.

The sequence of the identified proteins and homology analysis, performed using on-line available versions of BLAST search against UniProt Knowledgebase http:// www.expasy.ch/tools/blast, are reported in Additional file 1 Table $3 S$ and $4 S$.

Protein identification by gel-matching was automatically performed using A. balhimycina protein 2D reference-maps [23], available over the World Wide Web as interactive pages at http://www.unipa.it/ampuglia/Abalproteome-maps[24], and Image Master 2D platinum 7.0 software. More than 50 highly reproducible protein spots were used as landmarks to perform automatic gelmatching that was then verified by an accurate visual inspection using $3 \mathrm{D}$ view tool.

\section{Total RNA isolation, RT-PCR and qRT-PCR analysis}

Gene expression analysis at the transcriptional level of selected Pho regulon and bal genes was performed according to Gallo et al. 2010 [23]. The mycelia were resuspended in $1 \mathrm{ml} \mathrm{P}$-buffer [58] containing lysozyme $(1 \mathrm{mg} / \mathrm{ml})$ and RNase inhibitor RNaseOUT (Invitrogen) $(40 \mathrm{U} / \mathrm{ml})$, and then incubated for $10 \mathrm{~min}$, at $37^{\circ} \mathrm{C}$. The RNA was extracted by using the RNeasy midi kit (Qiagen) according to the manufacturer's instructions. DNase I (Roche) treatment was performed at $37^{\circ} \mathrm{C}$, for 1 $\mathrm{h}$, and ethanol precipitation in the presence of $0.1 \mathrm{vol}$ of $3 \mathrm{M}$ sodium acetate allowed recovery of the DNasetreated total RNA. After a washing step with $70 \%(\mathrm{v} / \mathrm{v})$ ethanol and air drying, the RNA pellet was resuspended in water with RNase inhibitor RNaseOUT $(200 \mathrm{U} / \mathrm{ml})$. As control of RNA quality, a RT-PCR with $0.1 \mu \mathrm{g}$ of total RNA and primer pairs internal to $h r d B$ was carried out using the Superscript One-Step RT-PCR kit (Invitrogen) and the conditions indicated by the supplier. PCRs were performed on $0.5 \mu \mathrm{g}$ of RNA samples using 40 cycles prior to exclude the presence of genomic DNA.

Primer pairs amplifying intragenic regions of the genes analysed by qRT-PCR are listed in Table 10S (Additional file 1). The identity of RT-PCR products was confirmed by sequencing. The high-capacity cDNA archive kit (Applied Biosystems) was used to retrotranscribe 2 $\mu \mathrm{g}$ of total RNA, extracted from LP and LG cultures, in a $100 \mu \mathrm{l}$ of water (final volume). Gene expression was analyzed quantitatively by using Applied Biosystems 7300 real-time PCR system (Applied Biosystems). The expression of $h r d B$ [23] was used as an internal control to quantify the relative expression of target genes. $2 \mu \mathrm{l}$ of cDNAs were mixed with $12.5 \mu$ of SYBR green PCR master mix (Applied Biosystem) and 10 pmol of each primer in a final volume of $25 \mu \mathrm{l}$. The PCR was performed under the following conditions: $2 \mathrm{~min}$ at $50^{\circ} \mathrm{C}$ and $10 \mathrm{~min}$ at $95^{\circ} \mathrm{C}$, followed by 40 cycles of $15 \mathrm{~s}$ at $95^{\circ} \mathrm{C}$ and $1 \mathrm{~min}$ at $60^{\circ} \mathrm{C}$. A dissociation reaction was eventually performed using a temperature gradient from 55 to $99^{\circ} \mathrm{C}$ by increasing $1^{\circ} \mathrm{C} / \mathrm{min}$. This procedure permitted recording the melting curve of the PCR products and, consequently, their specificity to be determined. A negative control (distilled water) was included in all real-time PCR assays, and each experiment was performed in triplicate or quadruplicate.

\section{Search for putative $\mathrm{PHO}$ box sequences}

A. balhimycina $\mathrm{PHO}$ box sequences were searched by matching two directs repeats (gttcacccggc and gttcatttacg) of S. coelicolor PHO box in the upstream region of $p s t S$ gene with regions extending $300 \mathrm{bp}$ upstream of the putative translation start sites of differentially expressed A. balhimycina genes. To this aim, on-line available versions of ClustalW http://www.ebi.ac.uk/ Tools/clustalw2/index.html[59] and EMBOSS GUI matcher http://bips.u-strasbg.fr/EMBOSS/[60] and BLAST bl2seq http://blast.ncbi.nlm.nih.gov/Blast.cgi[61] software were used. Only outputs derived from all the three approaches were accepted (Additional file 1 Table $6 \mathrm{~S}$ and $7 \mathrm{~S})$.

\section{Preparation of labeled DNA fragments}

DNA fragments containing the upstream regions of $S$. coelicolor pstS (PpstS: tccacaggggttcacccggcgttcatttacgcccttcggc) and the A. balhimycina pstS (PpstS: gaaaggcttgttcactttgcgttcatctggacaggggaac) and $p p k$ (Pppk: ggtatcgcgttgagctgttcatctgaccttcaccacgg) were prepared by incubation of the corresponding oligonucleotides at $90^{\circ} \mathrm{C}$ for $10 \mathrm{~min}$, followed by slow cooling to room temperature. The annealed products were recovered from nondenaturing $20 \%$ polyacrylamide gels by the crush-soak method [62] and labeled with T4 polynucleotide kinase (Invitrogen) according to the supplier's protocol.

\section{Preparation of $A$. balhimycina crude extract}

A. balhimycina pellet was washed twice with crack buffer (10 mM Tris-HCl, pH 8.0, $0.5 \mathrm{mM}$ EDTA, $0.3 \mathrm{mM}$ DTT), resuspended in $5 \mathrm{ml}$ of crack buffer, and disrupted by sonication. The cell debris was removed by centrifugation at $13,000 \times g\left(20 \mathrm{~min}, 4^{\circ} \mathrm{C}\right)$, and the supernatant was stored at $-80^{\circ} \mathrm{C}$.

\section{Gel mobility shift assay}

The gel mobility shift assay was performed according to Alduina et al., (2007) [14]. For the binding assay, A. balhimycina crude extract was dialyzed against distilled water over night at $4{ }^{\circ} \mathrm{C}$ and, then, approximately $200 \mu \mathrm{g}$ of proteins were incubated in $20 \mu \mathrm{l}$ of $12.5 \mathrm{mM}$ Tris$\mathrm{HCl}$ (pH 7.5), 10\% glycerol, $62.5 \mathrm{mM} \mathrm{KCl}, 0.75 \mathrm{mM}$ 
DTT, and $5 \mathrm{mM} \mathrm{MgCl}_{2}$, containing $100 \mu \mathrm{g}$ of poly(dI$\mathrm{dC}$ - poly $(\mathrm{dI}-\mathrm{dC}) \mathrm{ml}^{-1}$, for $10 \mathrm{~min}$, at $4^{\circ} \mathrm{C}$. After $15 \mathrm{~min}$ of incubation with $0.4 \mathrm{ng}$ of ${ }^{32} \mathrm{P}$-labeled DNA, complexes and free DNA were resolved on non-denaturing $5 \%$ polyacrylamide gels run in $0.5 \times$ Tris-borate-EDTA buffer at $150 \mathrm{~V}$ for approximately $2 \mathrm{~h}$ [54] and then equilibrated in $10 \%$ acetic acid, dried, and subjected to autoradiography. For testing the specificity of binding, either unlabeled probe or a competitor DNA fragment containing the upstream region of Nonomuraea sp ATCC $39727 d b v 14$ [14] were added before incubation of the proteins and probe.

\section{Declaration of competing interests}

The authors declare that they have no competing interests.

\section{Additional material}

\section{Additional file 1: .pdf contains $\mathbf{1 0}$ tables reporting: - amino acid} sequence of $A$. balhimycina Pho regulon gene products (Table 1S);-BLAST analysis of $\mathrm{PHO}$ regulon gene products against SwissProt database (Table 2S);-list of differential expressed proteins with information about their relative function, relative expression value, either theoretical and measured values for molecular weight (Mw) and isoelectric point (pl), protein identification method (Table 3S);-amino acid sequence of the MSidentified A. balhimycina proteins (Table 4S);-BLAST analysis data, obtained by using UniProt databank of proteins identified by MS analysis (Table 5S);-list of A. balhimycina DSM5908 genes arranged in putative operons (Table 65 );-sequence of upstream regions of selected $A$. balhimycina genes, showing $\mathrm{PHO}$ box directed repeats (DR) identified by ClustalW and BLAST bl2seq analysis performed by using S. coelicolor PHO box DR in the upstream regions of pstS (Table 7S);-EMBOSS-GUI Matcher analysis of $A$. balhimycina $\mathrm{PHO}$ box DR sequence performed by using $S$. coelicolor $\mathrm{PHO}$ box DR in the upstream regions of pstS (Table 8S); composition of fermentation media (Table 9S);-list of primers used for qRT-PCR experiments (Table 10S).

\begin{abstract}
Abbreviations
BDW: biomass dry weight. DPG: 3,5-dihydroxyphenylglycine. HPG: 4hydroxyphenylglycine. H-Tyr: $\beta$-hydroxytyrosine. LG: limiting glucose and high phosphate. LP: low phosphate and proficient glucose. $\bar{M} S$ : mass spectrometry. Pi: inorganī phosphate.
\end{abstract}

\section{Acknowledgements}

The authors acknowledge Wolfgang Wohlleben, Efthimia Stegmann and Tilmann Weber, for giving us the possibility to access to the Amycolatopsis balhimycina DSM5908 genome sequence and ORF product databases. The authors also thank Fabio Sangiorgi for his contribution to the "Amycolatopsis balhimycina Proteomic Project" web pages and Maurizio Noto for technical assistance.

This study was partly supported by grants from the European Union (LSHBCT-2003-503491 and LSHM-CT-2004-005224), MIUR (ex 60\%) to AMP and Rete di Spettrometria di Massa RESMAC (Regione Campania) to AS.

\section{Author details}

${ }^{1}$ Università di Palermo, Dipartimento di Biologia Cellulare e dello Sviluppo, Viale delle Scienze, Parco d'Orleans II, 90128 Palermo, Italy. ${ }^{2}$ Proteomics \& Mass Spectrometry Laboratory, ISPAAM, National Research Council, 80147 Naples, Italy. ${ }^{3}$ Center for Microbial Biotechnology, Department of Systems Biology, Technical University of Denmark, Denmark.

\section{Authors' contributions}

GG carried out chemostat cultivations, DIGE analysis, protein identification by gel-matching, real-time RT-PCR and EMSA experiments, BLAST analyses and wrote the draft manuscript. RA helped to perform real-time RT-PCR and EMSA experiments and to wrote the draft manuscript. GR carried out protein MS-identification. JT designed chemostat experiments, helped to perform chemostat cultivations and revised the manuscript. LB helped to perform protein MS-identification. AEL supervised chemostat experiments and revised the manuscript. AS supervised protein MS-identification and revised the manuscript. AMP conceived and supervised the study and participated in its design and coordination and revised the manuscript.

All authors read and approved the final manuscript.

Received: 12 August 2010 Accepted: 26 November 2010 Published: 26 November 2010

\section{References}

1. Finch R, Eliopoulos G: Safety and efficacy of glycopeptide antibiotics. J Antimicrob Chemother 2005, 55(Suppl 2):ii5-13.

2. Nadkarni S, Patel M, Chatterjee S, Vijayakumar E, Desikan K, Blumbach J, Ganguli B, Limbert M: Balhimycin, a new glycopeptide antibiotic produced by Amycolatopsis sp. Y-86,21022. Taxonomy, production, isolation and biological activity. J Antibiot (Tokyo) 1994, 47(3):334-341.

3. Chatterjee D, Sarma P, Jani R, Klesel N, Isert D: Comparative chemotherapeutic efficacy of balhimycin, desgluco-balhimycin against experimental MSSA and MRSA infection in mice. Indian J Exp Biol 2000, 38(7):681-686.

4. Pelzer S, Süssmuth R, Heckmann D, Recktenwald J, Huber P, Jung G Wohlleben W: Identification and analysis of the balhimycin biosynthetic gene cluster and its use for manipulating glycopeptide biosynthesis in Amycolatopsis mediterranei DSM5908. Antimicrob Agents Chemother 1999, 43(7):1565-1573.

5. Shawky R, Puk O, Wietzorrek A, Pelzer S, Takano E, Wohlleben W, Stegmann $E$ : The border sequence of the balhimycin biosynthesis gene cluster from Amycolatopsis balhimycina contains bbr, encoding a StrRlike pathway-specific regulator. J Mol Microbiol Biotechnol 2007, 13(13):76-88.

6. Süssmuth $\mathrm{R}$, Wohlleben $\mathrm{W}$ : The biosynthesis of glycopeptide antibiotics-a model for complex, non-ribosomally synthesized, peptidic secondary metabolites. Appl Microbiol Biotechnol 2004, 63(4):344-350.

7. Demain A: Induction of microbial secondary metabolism. Int Microbiol 1998, 1(4):259-264.

8. Chakraburtty $R$, Bibb M: The ppGpp synthetase gene $(r e l A)$ of Streptomyces coelicolor A3(2) plays a conditional role in antibiotic production and morphological differentiation. J Bacteriol 1997, 179(18):5854-5861.

9. Martín J, Liras P: Engineering of regulatory cascades and networks controlling antibiotic biosynthesis in Streptomyces. Curr Opin Microbiol 2010, 13(3):263-273.

10. Mclntyre J, Bull A, Bunch A: Vancomycin production in batch and continuous culture. Biotechnol Bioeng 1996, 49(4):412-420.

11. Ayar-Kayali $H$, Tarhan L: Vancomycin antibiotic production and TCAglyoxalate pathways depending on the glucose concentration in Amycolatopsis orientalis. Enzyme Microbiol Technol 2006, 38:727-734

12. Maiti S, Singh K, Lantz A, Bhushan M, Wangikar P: Substrate uptake, phosphorus repression, and effect of seed culture on glycopeptide antibiotic production: process model development and experimental validation. Biotechnol Bioeng 2010, 105(1):109-120.

13. Gunnarsson N, Bruheim P, Nielsen J: Production of the glycopeptide antibiotic A40926 by Nonomuraea sp. ATCC 39727: influence of medium composition in batch fermentation. J Ind Microbiol Biotechnol 2003, 30(3):150-156.

14. Alduina R, Lo Piccolo L, D'Alia D, Ferraro C, Gunnarsson N, Donadio S, Puglia A: Phosphate-controlled regulator for the biosynthesis of the dalbavancin precursor A40926. J Bacteriol 2007, 189(22):8120-8129.

15. Sola-Landa A, Moura R, Martín J: The two-component PhoR-PhoP system controls both primary metabolism and secondary metabolite biosynthesis in Streptomyces lividans. Proc Natl Acad Sci USA 2003, 100(10):6133-6138. 
16. Rodríguez-García A, Barreiro C, Santos-Beneit F, Sola-Landa A, Martín J: Genome-wide transcriptomic and proteomic analysis of the primary response to phosphate limitation in Streptomyces coelicolor M145 and in a $\triangle$ phoP mutant. Proteomics 2007, 7(14):2410-2429.

17. Sola-Landa A, Rodríguez-García A, Franco-Domínguez E, Martín J: Binding of PhoP to promoters of phosphate-regulated genes in Streptomyces coelicolor: identification of PHO boxes. Mol Microbiol 2005, 56(5):1373-1385.

18. Sola-Landa A, Rodríguez-García A, Apel A, Martín J: Target genes and structure of the direct repeats in the DNA-binding sequences of the response regulator PhoP in Streptomyces coelicolor. Nucleic Acids Res 2008, 36(4):1358-1368

19. Apel A, Sola-Landa A, Rodríguez-García A, Martín J: Phosphate control of phoA, phoC and phoD gene expression in Streptomyces coelicolor reveals significant differences in binding of PhoP to their promoter regions. Microbiology 2007, 153(Pt 10):3527-3537.

20. Makarewicz O, Dubrac S, Msadek T, Borriss R: Dual role of the PhoP approximately $\mathrm{P}$ response regulator Bacillus amyloliquefaciens FZB45 phytase gene transcription is directed by positive and negative interactions with the phyC promoter. J Bacteriol 2006, 188(19):6953-6965.

21. Papini M, Salazar M, Nielsen J: Systems Biology of Industrial Microorganisms. Adv Biochem Eng Biotechnol 2010, 120:51-99.

22. Park J, Lee $\mathrm{S}, \mathrm{Kim} \mathrm{T}$, Kim H: Application of systems biology for bioprocess development. Trends Biotechnol 2008, 26(8):404-412.

23. Gallo G, Renzone G, Alduina R, Stegmann E, Weber T, Lantz A, Thykaer J, Sangiorgi F, Scaloni A, Puglia A: Differential proteomic analysis reveals novel links between primary metabolism and antibiotic production in Amycolatopsis balhimycina. Proteomics 2010, 10(7):1336-1358.

24. Amycolatopsis balhimycina Proteomic Project. [http://www.unipa.it/ ampuglia/Abal-proteome-maps].

25. Thykaer J, Nielsen J, Wohlleben W, Weber T, Gutknecht M, Lantz A, Stegmann E: Increased glycopeptide production after overexpression of shikimate pathway genes being part of the balhimycin biosynthetic gene cluster. Metab Eng 2010, 12(5):455-6.

26. Ghorbel S, Smirnov A, Chouayekh H, Sperandio B, Esnault C, Kormanec J, Virolle M: Regulation of ppk expression and in vivo function of Ppk in Streptomyces lividans TK24. J Bacteriol 2006, 188(17):6269-6276.

27. Chouayekh $H$, Virolle M: The polyphosphate kinase plays a negative role in the control of antibiotic production in Streptomyces lividans. Mol Microbiol 2002, 43(4):919-930.

28. ExPASy Proteomic server. [http://expasy.org/]

29. Shi X, Rao N, Kornberg A: Inorganic polyphosphate in Bacillus cereus: motility, biofilm formation, and sporulation. Proc Natl Acad Sci USA 2004 101(49):17061-17065.

30. Zhang H, Rao N, Shiba T, Kornberg A: Inorganic polyphosphate in the social life of Myxococcus xanthus: motility, development, and predation. Proc Natl Acad Sci USA 2005, 102(38):13416-13420.

31. Walsh C, Fisher S, Park I, Prahalad M, Wu Z: Bacterial resistance to vancomycin: five genes and one missing hydrogen bond tell the story. Chem Biol 1996, 3(1):21-28[http://biocyc.org/], BioCyc Database Collection.

32. BioCyc Database Collection. [http://biocyc.org/].

33. KEGG: Kyoto Encyclopedia of Genes and Genomes.[http://www.genome. jp/kegg/].

34. Copp J, Neilan B: The phosphopantetheinyl transferase superfamily: phylogenetic analysis and functional implications in cyanobacteria. Appl Environ Microbiol 2006, 72(4):2298-2305

35. Matsubara K, Ohnishi K, Kiritani K: Nucleotide sequences and characterization of liv genes encoding components of the high-affinity branched-chain amino acid transport system in Salmonella typhimurium. J Biochem 1992, 112(1):93-101.

36. Bordignon $\mathrm{E}$, Grote $\mathrm{M}$, Schneider $\mathrm{E}$ : The maltose ATP-binding cassette transporter in the 21st century-towards a structural dynamic perspective on its mode of action. Mol Microbiol 2010, 77(6):1354-1366.

37. Gunnarsson N, Bruheim P, Nielsen J: Glucose metabolism in the antibiotic producing actinomycete Nonomuraea sp. ATCC 39727. Biotechnol Bioeng 2004, 88(5):652-663.

38. Muschko K, Kienzlen G, Fiedler H, Wohlleben W, Schwartz D: Tricarboxylic acid cycle aconitase activity during the life cycle of Streptomyces viridochromogenesTü494. Arch Microbiol 2002, 178(6):499-505.

39. Schwartz D, Kaspar S, Kienzlen G, Muschko K, Wohlleben W: Inactivation of the tricarboxylic acid cycle aconitase gene from Streptomyces viridochromogenes Tü494 impairs morphological and physiological differentiation. J Bacteriol 1999, 181(22):7131-7135.

40. Viollier P, Nguyen K, Minas W, Folcher M, Dale G, Thompson C: Roles of aconitase in growth, metabolism, and morphological differentiation of Streptomyces coelicolor. J Bacteriol 2001, 183(10):3193-3203.

41. Summers M, Denton M, McDermott T: Genes coding for phosphotransacetylase and acetate kinase in Sinorhizobium meliloti are in an operon that is inducible by phosphate stress and controlled by phoB. J Bacteriol 1999, 181(7):2217-2224

42. Antelmann $H$, Scharf $C$, Hecker M: Phosphate starvation-inducible proteins of Bacillus subtilis: proteomics and transcriptional analysis. J Bacteriol 2000, 182(16):4478-4490.

43. Moreau P, Gérard F, Lutz N, Cozzone P: Non-growing Escherichia coli cells starved for glucose or phosphate use different mechanisms to survive oxidative stress. Mol Microbiol 2001, 39(4):1048-1060.

44. Krol E, Becker A: Global transcriptional analysis of the phosphate starvation response in Sinorhizobium meliloti strains 1021 and 2011. Mol Genet Genomics 2004, 272(1):1-17.

45. Carrondo M: Ferritins, iron uptake and storage from the bacterioferritin viewpoint. EMBO J 2003, 22(9):1959-1968.

46. Snider J, Houry W: MoxR AAA+ ATPases: a novel family of molecular chaperones? J Struct Biol 2006, 156(1):200-209.

47. Sengupta J, Agrawal R, Frank J: Visualization of protein S1 within the $30 \mathrm{~S}$ ribosomal subunit and its interaction with messenger RNA. Proc Natl Acad Sci USA 2001, 98(21):11991-11996.

48. Gilbert H, Lowe C, Drabble W: Inosine 5'-monophosphate dehydrogenase of Escherichia coli. Purification by affinity chromatography, subunit structure and inhibition by guanosine $5^{\prime}$-monophosphate. Biochem J 1979, 183(3):481-494.

49. Kudo F, Kawabe K, Kuriki H, Eguchi T, Kakinuma K: A new family of glucose-1-phosphate/glucosamine-1-phosphate nucleotidylyltransferase in the biosynthetic pathways for antibiotics. J Am Chem Soc 2005, 127:1711-1718.

50. Copp J, Neilan B: The phosphopantetheinyl transferase superfamily: phylogenetic analysis and functional implications in cyanobacteria. Appl Environ Microbiol 2006, 72(4):2298-2305.

51. Hubbard B, Walsh C: Vancomycin assembly: nature's way. Angew Chem Int Ed Engl 2003, 42(7):730-765.

52. WebLogo. [http://weblogo.berkeley.edu/].

53. Borodina I, Siebring J, Zhang J, Smith C, van Keulen G, Dijkhuizen L, Nielsen J: Antibiotic overproduction in Streptomyces coelicolor A3 2 mediated by phosphofructokinase deletion. J Biol Chem 2008, 283(37):25186-25199.

54. Butler M, Bruheim P, Jovetic S, Marinelli F, Postma P, Bibb M: Engineering of primary carbon metabolism for improved antibiotic production in Streptomyces lividans. Appl Environ Microbiol 2002, 68(10):4731-4739.

55. Avignone Rossa C, White J, Kuiper A, Postma P, Bibb M, Teixeira de Mattos M: Carbon flux distribution in antibiotic-producing chemostat cultures of Streptomyces lividans. Metab Eng 2002, 4(2):138-150.

56. D'Ambrosio C, Arena S, Salzano A, Renzone G, Ledda L, Scaloni A: A proteomic characterization of water buffalo milk fractions describing PTM of major species and the identification of minor components involved in nutrient delivery and defense against pathogens. Proteomics 2008, 8(17):3657-3666

57. Scippa G, Rocco M, Ialicicco M, Trupiano D, Viscosi V, Di Michele M, Arena S, Chiatante D, Scaloni A: The proteome of lentil (Lens culinaris Medik.) seeds: discriminating between landraces. Electrophoresis 2010, 31(3):497-506

58. Kieser T, Bibb MJ, Buttner MJ, Chater KF, Hopwood DA: Practical Streptomyces genetics. John Innes Foundation, Norwich, United Kingdom; 2000.

59. ClustalW. [http://www.ebi.ac.uk/Tools/clustalw2/index.html].

60. EMBOSS GUI. [http://bips.u-strasbg.fr/EMBOSS/].

61. BLAST. [http://blast.ncbi.nlm.nih.gov/Blast.cgi].

62. Sambrook J, Fritsch EF, Maniatis T: Molecular cloning: a laboratory manual. Cold Spring Harbor Laboratory, New York, NY; 1982.

doi:10.1186/1475-2859-9-95

Cite this article as: Gallo et al:: Differential proteomic analysis highlights metabolic strategies associated with balhimycin production in Amycolatopsis balhimycina chemostat cultivations. Microbial Cell Factories 2010 9:95. 